\title{
An open-label, single-dose study to evaluate the safety, tolerability, pharmacokinetics, and pharmacodynamics of cinacalcet in pediatric subjects aged 28 days to $<6$ years with chronic kidney disease receiving dialysis
}

\author{
Winnie Y. Sohn ${ }^{1}$ (D) - Anthony A. Portale ${ }^{2}$ - Isidro B. Salusky ${ }^{3} \cdot$ Hao Zhang ${ }^{1} \cdot$ Lucy L. Yan $^{1} \cdot$ Bella Ertik ${ }^{1}$. \\ Shahnaz Shahinfar ${ }^{4} \cdot$ Edward Lee $^{1} \cdot$ Bastian Dehmel $^{1} \cdot$ Bradley A. Warady $^{5}$
}

Received: 8 May 2018 /Revised: 7 August 2018 / Accepted: 10 August 2018 / Published online: 23 August 2018

(C) The Author(s) 2018

\begin{abstract}
Background Calcimimetics, shown to control biochemical parameters of secondary hyperparathyroidism (SHPT), have wellestablished safety and pharmacokinetic profiles in adult end-stage renal disease subjects treated with dialysis; however, such studies are limited in pediatric subjects.

Methods In this study, the safety, tolerability, pharmacokinetics (PK), and pharmacodynamics (PD) of cinacalcet were evaluated in children with chronic kidney disease (CKD) and SHPT receiving dialysis. Twelve subjects received a single dose of cinacalcet $(0.25 \mathrm{mg} / \mathrm{kg})$ orally or by nasogastric or gastric tube. Subjects were randomized to one of two parathyroid hormone (PTH) and serum calcium sampling sequences: [(1) 2, 8, $48 \mathrm{~h}$; or (2) 2, 12, $48 \mathrm{~h}]$ and assessed for $72 \mathrm{~h}$ after dosing.

Results Median plasma cinacalcet $t_{\max }$ was $1 \mathrm{~h}$ (range 0.5-4.0 h); mean (SD) $C_{\max }$ and $\mathrm{AUC}_{\text {last }}$ were $2.83(1.98) \mathrm{ng} / \mathrm{mL}$ and 11.8 (8.74) $\mathrm{h} * \mathrm{ng} / \mathrm{mL}$, respectively; mean (SD) half-life $\left(t_{1 / 2}\right)$ was $3.70(2.57) \mathrm{h}$. Dose adjustments, based upon body weight $(\mathrm{mg} / \mathrm{kg})$, minimized the effects of age, body weight, body surface area, and body mass index on cinacalcet PK. Reductions in serum PTH levels from baseline were observed at 2 to $8 \mathrm{~h}$ post-dose (median 10.8 and $29.6 \%$, respectively), returned towards baseline by 12 $72 \mathrm{~h}$ and were inversely related to changes in the plasma cinacalcet PK profile. Single-dose cinacalcet was well-tolerated with no unexpected safety findings and a PK/PD, safety profile similar to adults.

Conclusions In conclusion, a single $0.25 \mathrm{mg} / \mathrm{kg}$ dose of cinacalcet was evaluated to be a safe starting dose in these children aged $<6$ years.
\end{abstract}

Keywords Calcimimetics $\cdot$ Cinacalcet $\cdot$ Chronic kidney disease $\cdot$ Parathyroid hormone $\cdot$ Pediatric dialysis patients $\cdot$ Secondary hyperparathyroidism

Winnie Y. Sohn

wkim@amgen.com

1 Amgen, Inc., One Amgen Center Dr. M/S 38-4-A, Thousand Oaks, CA 91320, USA

2 UCSF Benioff Children's Hospital, San Francisco, CA, USA

3 David Geffen School of Medicine at UCLA, Los Angeles, CA, USA

4 S. Shahinfar Consulting and Childrens Hospital of Philadelphia, Philadelphia, PA, USA

5 Children's Mercy Hospital, Kansas City, MO, USA

\section{Introduction}

Chronic kidney disease-mineral and bone disorder (CKDMBD) is a systemic disorder of mineral and bone metabolism due to CKD manifested by abnormalities of calcium, phosphorus, parathyroid hormone (PTH), or vitamin D metabolism; abnormalities of bone turnover, mineralization, volume, linear growth, or strength; and vascular or other soft tissue calcification [1,2]. Secondary hyperparathyroidism (SHPT) develops in the course of CKD, and its prevalence and severity increase as CKD progresses towards end-stage renal disease (ESRD) [3-7]. Secondary 
hyperparathyroidism is associated with adverse outcomes including cardiovascular complications, vascular calcification, heart failure, calciphylaxis, bone pain, bone deformities, and increased risk of fracture [7-11]. The long-term consequences of CKD-MBD on the growing skeleton are characterized by changes in the cardiovascular system, bone, disordered skeletal development, and growth impairment [12-15]. The overall mortality rate in children with ESRD is 30 -fold greater than in their healthy peers, with a large proportion of the mortality due to cardiovascular disease (CVD) [16].

Active vitamin $\mathrm{D}\left(1,25(\mathrm{OH})_{2} \mathrm{D}_{3}\right)$, vitamin $\mathrm{D}$ analogs, and phosphate binders are the most common treatments for SHPT; however, such therapies may not fully treat SHPT and have the potential to increase the risk of vascular calcification by increasing serum calcium and phosphorus levels [17]. In addition, fracture risk, bone deformities, and growth retardation [9] may not adequately respond to active vitamin D analogs given to suppress SHPT [18], and a bone mineralization defect is persistent despite therapy with active vitamin D sterols [18]. Finally, whereas parathyroidectomy has been conducted to treat unresponsive SHPT, children ( $\leq 17$ years of age) have significantly higher general and endocrine-specific complication rates after parathyroidectomy than adults $[19,20]$. Interestingly, children aged $\leq 6$ years have been found to have significantly longer hospital stays and higher complication rates than children aged 7-12 years and 13-17 years [19].

Cinacalcet (Sensipar ${ }^{\circledR / M i m p a r a}{ }^{\circledR}$, Amgen Inc., Thousand Oaks, CA) is a first in-class calcimimetic that is indicated for the treatment of SHPT in adult subjects with CKD receiving dialysis [21]. The safety and efficacy of cinacalcet in adults with CKD and SHPT receiving dialysis has been extensively investigated [22-25], and its use, along with calcitriol, or vitamin D analogs, or a combination thereof, is included in the Kidney Disease Improving Global Outcomes (KDIGO) clinical practice guidelines for PTH lowering in adult subjects with stage 5 CKD receiving dialysis [1]. While calcimimetics have been shown to effectively control biochemical parameters in adult ESRD subjects with associated SHPT receiving dialysis, and severe SHPT with hypercalcemia after renal transplantation [26], the safety and efficacy of these agents in children needs to be further investigated [10]. In addition, while single-dose safety, pharmacokinetic (PK), and pharmacodynamic (PD) data have been published for children $>$ 6 years of age, similar data from younger children have not previously been reported [27-29].

The objectives of this study were to evaluate the safety, tolerability, PK, and PD effects of cinacalcet after a single dose to pediatric subjects aged 28 days to $<6$ years with
CKD receiving dialysis. In addition, the study evaluated the safety of a $0.25 \mathrm{mg} / \mathrm{kg}$ starting dose, in pediatric subjects under the age of 6 years.

\section{Methods}

We conducted a phase 1, open-label study designed to evaluate the safety, tolerability, PK, and PD of cinacalcet in subjects aged 28 days to $<6$ years with CKD and SHPT undergoing hemodialysis or peritoneal dialysis. The study was conducted in seven centers located in four countries. The first subject was enrolled on January 25, 2011, and the completion date was August 25, 2015 (Fig. 1).

Twelve subjects ( $<6$ years old) who met inclusion and exclusion criteria (Table 1) were enrolled to receive a single dose of $0.25 \mathrm{mg} / \mathrm{kg}$ cinacalcet. Cinacalcet was supplied as 5-mg capsules that were not to be swallowed whole. The capsules were opened and the contents mixed with purified water or USP-NF sucrose syrup and administered orally (syringe) or by nasogastric or gastric $(\mathrm{NG} / \mathrm{G})$ tube. If possible, subjects fasted from $2 \mathrm{~h}$ pre-dose to $2 \mathrm{~h}$ post-dose on day 1 . If fasting was not possible, the subject's intake of food (liquids and solids) was recorded in the electronic case report form (eCRF). For subjects undergoing dialysis on study day -1 through day 4 , information pertaining to the procedure (i.e., date (s), mode of dialysis, start and stop times, and dialysate composition [amount of calcium and potassium]) was recorded in the subject's chart and in the appropriate eCRF. Based on the available data, half of the subjects received peritoneal dialysis and the other half received hemodialysis. It should be noted that hemodialysis or peritoneal dialysis does not impact cinacalcet PK or PD response [30]. All subjects received active vitamin D; two subjects (one in the 28 days to $<3$ year age group and another in the $\geq 3$ to $<6$ year age group) received calcium-based phosphorus binders (Ca carbonate).

Blood sampling at pre-defined time intervals post-dose was performed to assess cinacalcet pharmacokinetics and pharmacodynamics.

\section{Assessments}

Blood samples were collected to measure PTH using an immunometric assay (ADVlA Centaur PTH Assay, Siemens Healthcare, Erlangen, Germany), total serum calcium, and albumin 1 day before (day -1$)$ cinacalcet was administered. Serum calcium was reported as total calcium or as the albumin-corrected value by the central laboratory based on calcium and albumin concentrations. In addition, ionized calcium was measured in whole blood samples to 
Table 1 Inclusion and exclusion criteria

\section{Key inclusion criteria}

Age 28 days to $<6$ years with CKD and sHPT, undergoing hemodialysis or peritoneal dialysis at screening (subjects $\geq 6$ months should have been receiving dialysis for $\geq 1$ month)

Free of any disease or condition (other than those diseases or conditions related to their renal disease)

Body weight $\geq 6 \mathrm{~kg}$ at screening and at day -1 ; gestational age 30 weeks; physical examination must be acceptable to investigator at screening and at day -1

Serum calcium within age-appropriate normal ranges per NKF-K/DOQI guidelines at screening and at day -1

Hemoglobin $\geq 8 \mathrm{~g} / \mathrm{dL}$ at screening and at day -1

Normal or clinically acceptable ECGs at screening and at day 1

Key exclusion criteria

Current or historic malignancy

Cardiac ventricular arrhythmias within 28 days prior to screening

A gastrointestinal disorder or surgery that could affect drug absorption (e.g., pyloric stenosis or any gut-shortening surgical procedure prior to screening)

A new onset of seizure or worsening of a pre-existing seizure disorder within 2 months prior to IP administration

Major surgery (defined as any surgical procedure that involves general anesthesia or respiratory assistance) within 28 days prior to screening

Received therapy with cinacalcet within 1 month prior to randomization Clinical lab signs of hepatic impairment

Medications: use of grapefruit juice, herbal medications, or potent CYP 3A4 inhibitors (e.g., erythromycin, clarithromycin, ketokonazole, itraconazole) within 14 days prior to enrollment and during study

Concurrent or within 28 days prior to enrollment use of medications that are predominantly metabolized by the enzyme CYP2D6 with a narrow therapeutic index; use of medications that prolong QT interval

$C K D$ chronic kidney disease, $s H P T$ secondary hyperparathyroidism, $N K F-K D O Q I$ National Kidney Foundation Kidney Disease Outcomes Quality Initiative, $E C G$ electrocardiogram, $I P$ intraperitoneal

rapidly and efficiently monitor calcium status (e.g., normocalcemia, hypocalcemia). For all subjects, blood samples for PK and PD analyses were collected pre-dose. Subjects were randomized to undergo one of two sampling sequences post-dose: (1) sampling at 2, 8 , and $48 \mathrm{~h}$; or (2) sampling at 2, 12, and $48 \mathrm{~h}$. Subjects were assessed clinically, including safety monitoring, for up to $72 \mathrm{~h}$ after dosing. Subjects were monitored carefully for the occurrence of hypocalcaemia (clinical symptoms, as well as serum calcium levels). In the event that serum calcium levels decreased below $8.4 \mathrm{mg} / \mathrm{dL}(2.1 \mathrm{mmol} / \mathrm{L})$ and/or symptoms of hypocalcaemia occurred, the following options were recommended to investigators: calcium-containing phosphate binders, vitamin D sterols, and/or adjustment of dialysate calcium concentrations to raise serum calcium, according to clinical judgment. Serum phosphate was managed to achieve concentrations within age-appropriate ranges per National Kidney Foundation-Kidney Disease Outcomes Quality Initiative (NKF-K/DOQI) guidelines [1].

For determination of plasma cinacalcet concentrations, plasma samples were obtained and analysis was performed using high-performance liquid chromatography followed by tandem mass spectrometric detection (LC-MS/MS) at Covance (Madison, WI). The calibration standards and QC samples were interspersed with study samples within each analytical run, with a validated analytical range of 0.100 to $25 \mathrm{ng} / \mathrm{mL}$. A total of 130 samples were analyzed and the overall precision and (mean) accuracy of the QC samples of all analytical runs were within the acceptance criteria. All study samples were analyzed within the known stability period of 347 days when stored at -10 to $-30{ }^{\circ} \mathrm{C}$. Pharmacokinetic (PK) analyses were conducted using Pharsight Knowledgebase Server system version 4.0.3 (Pharsight ${ }^{\circledR}$, St. Louis, MO). Cinacalcet plasma concentration-time data was used to determine the PK parameters using non-compartmental methods (Phoenix WinNonlin v.6.4 software on Citrix [Pharsight ${ }^{\circledR}$, St. Louis, Missouri]). Plasma concentrations below the lower limit of quantification (LLOQ; $0.100 \mathrm{ng} / \mathrm{mL}$ ) were set to zero for the estimation of PK parameters for each subject and for the calculation of summary statistics at each time point. Actual dosing and sampling times were used for all calculations.

\section{Study endpoints}

The primary endpoint of the study was the incidence of treatment-emergent adverse events (AEs), clinically significant changes in physical examinations, laboratory safety tests, electrocardiograms (ECG), and vital signs. The secondary endpoints included the PK parameters of cinacalcet (area under the plasma concentration-time curve (AUC), maximum observed plasma concentration $\left(C_{\max }\right)$, time to $C_{\max }\left[t_{\max }\right]$, and half-life [ $\left.\left.t_{1 / 2}\right]\right)$ and PD parameters of PTH and serum levels of calcium (total calcium, albumin corrected serum calcium [cCa], and ionized calcium). Safety endpoints included nature, frequency, severity, and relationship to treatment of all AEs; incidence of hypocalcemia; and vital signs and changes in laboratory parameters, including clinical chemistry.

\section{Statistical analysis and determination of sample size}

The sample size was based on the variability of change from baseline in serum calcium in response to cinacalcet administered to pediatric patients 6 to $<18$ years (Amgen Study 20030227) throughout the efficacy assessment phase (EAP), 
weeks 17-20. A power analysis of data collected from 12 subjects (standard deviation $=0.53 \mathrm{mg} / \mathrm{dL}$ ) was calculated to have $80 \%$ power to detect a $0.48 \mathrm{mg} / \mathrm{dL}$ reduction in serum calcium from baseline ( $\alpha=0.05$, two-sided). Descriptive statistics were provided for selected demographic, safety, PK, and PD data for all subjects. Descriptive statistics on continuous data included means, medians, standard deviations, and ranges, while categorical data were summarized using frequency counts and percentages.

\section{Safety monitoring and review}

Treatment emergent AEs were grouped by system organ class and by preferred term within system organ class according to the Medical Dictionary for Regulatory Activities (MedDRA) AE-preferred term dictionary version 18.0. Determination of the severity of all AEs was consistent with Common Terminology Criteria for Adverse Events (CTCAE) V. 4.0 unless specified otherwise. The number and percent of subjects reporting at least one treatmentemergent $\mathrm{AE}$ and each treatment-emergent $\mathrm{AE}$ were summarized by system organ class and preferred term over all subjects and further classified by relationship to treatment. Tables of "on-study" deaths, serious AEs, and early withdrawals due to AEs were provided when necessary.

\section{Results}

\section{Demographic and baseline characteristics}

Fourteen subjects were initially enrolled into the study including five subjects 28 days to $<3$ years of age and nine subjects $\geq$ 3 years to $<6$ years of age. One subject in each age group discontinued the study prior to receiving cinacalcet. Thus, four subjects in the original 28 days to $<3$ years age group and eight subjects in the $\geq 3$ years to $<6$ years age group completed the study. Among those patients who completed the study, the mean age was 18.8 months (range 8 to 34 months) for the younger group subjects ( $<3$ years), 51.5 months (range 44 to 61 months) for subjects $\geq 3$ years to $<6$ years, and 40.6 months (range 8 to 61 months) for all subjects. Mean baseline concentrations of $\mathrm{PTH}$, corrected calcium, and phosphorus were $536.2 \mathrm{pg} / \mathrm{mL}$, $2.6 \mathrm{mmol} / \mathrm{L}$, and $1.8 \mathrm{mmol} / \mathrm{L}$, respectively; the mean baseline $\mathrm{Ca} \times \mathrm{P}$ product was $58.6 \mathrm{mg}^{2} / \mathrm{dL}^{2}$.

\section{Primary endpoint}

All subjects were monitored for adverse events following a single oral dose of $0.25 \mathrm{mg} / \mathrm{kg}$ cinacalcet. Five treatmentemergent AEs were reported for $3(25 \%)$ of 12 subjects, including $1(25 \%)$ of 4 subjects $<3$ years old, and $2(25 \%)$ of 8 subjects $\geq 3$ years to $<6$ years old. There were no serious or fatal AEs. Adverse events reported for one subject (34 months old) were vomiting, catheter site hemorrhage, and catheter expulsion. Adverse events reported for two subjects $\geq 3$ years to $<6$ years old were increased body temperature (age 61 months) and hypocalcemia (treatment-related adverse event of interest, age 45 months).

There were no life-threatening (grade 4) events reported during the study. Severe (grade 3) events included one event each of catheter site hemorrhage, device expulsion (chest catheter falling out), and hypocalcemia (asymptomatic, non-serious) that resolved without treatment on day 3 after start of the treatment. The patient who experienced asymptomatic hypocalcemia (non-serious adverse event, CTCAE grade 3 ) on day 1 , hour 8 after cinacalcet administration was a female with baseline total $\mathrm{Ca}=2.1 \mathrm{mmol} / \mathrm{L}$; albumin corrected $\mathrm{Ca}(\mathrm{cCa})=2.2 \mathrm{mmol} / \mathrm{L}$, ionized $\mathrm{Ca}=0.9 \mathrm{mmol} /$ $\mathrm{L}$ (in the normal range for pediatric subjects) with an elevated baseline PTH of $126.4 \mathrm{pmol} / \mathrm{L}(1191 \mathrm{pg} / \mathrm{mL})$, and a phosphorus $=1.71 \mathrm{mmol} / \mathrm{L}$. The patient was undergoing hemodialysis with a dialysate calcium content of $3 \mathrm{mg} / \mathrm{dL}$ and received active vitamin $\mathrm{D}, \mathrm{Ca}$ carbonate, antihypertensives (amlodipine, isradipine, labetalol), sevelamer, docusate, sodium polystyrene sulfonate (K binder), and pyridoxine. Changes observed in laboratory test results (e.g., chemistry and hematology data) were consistent with the disease states under study. No notable changes from baseline were observed for vital signs measurements or ECG results.

\section{Secondary endpoints}

\section{Pharmacokinetics}

Cinacalcet was rapidly absorbed, with a median $t_{\max }$ of $1 \mathrm{~h}$ (range 0.50 to 4.0 h) (Table 2, Fig. 2). The mean (SD) halflife $\left(t_{1 / 2, z}\right)$ was $3.70(2.57) \mathrm{h}$ (Table 2). Plasma cinacalcet mean (SD) $C_{\max }$ and $\mathrm{AUC}_{\text {last }}$ in all subjects $<6$ years of age were $2.83(1.98) \mathrm{ng} / \mathrm{mL}$ and $11.8(8.74) \mathrm{h} * \mathrm{ng} / \mathrm{mL}$, respectively (Table 2). While overall there was no clinically meaningful difference in cinacalcet exposure between the age groups due to extensive overlap and high inter-subject variability (coefficient of variation [CV\%] range 54.5 to 75.7) (Fig. 3), there was a trend for slightly higher exposures in subjects $\geq 3$ to $<6$ years old compared to subjects $<3$ years old. Mean plasma cinacalcet $C_{\max }$ and AUC values appeared to be marginally higher (1.6- to 2.3-fold) in subjects $\geq 3$ to $<6$ years old compared with subjects $<$ 3 years old, but individual values were within a similar range. There were no notable effects of age, weight, body surface area, and BMI on the PK of cinacalcet, based on an 


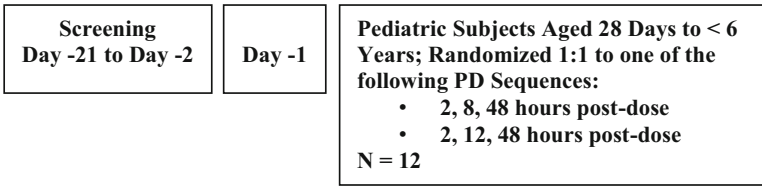

\begin{tabular}{|c|c|c|}
\hline Day 4 & Day 4 & Day 30 \\
E & A \\
N & E \\
D & S \\
& A \\
O & F \\
F & O \\
L & F \\
S & L \\
O \\
T & W \\
W & L \\
O \\
D & W \\
Y & P \\
& & U \\
& & \\
\hline
\end{tabular}

Fig. 1 Study design and treatment schema. Screening was conducted between days -21 to -2 . Subjects entered the clinical unit on day -1 to undergo safety laboratory testing and baseline PD sampling and remained in residency until 24 -h post-dose procedures were completed. Following pre-dose procedures and dosing on day 1, subjects

assessment of the impact of these characteristics on cinacalcet $C_{\max }$ and AUC values.

\section{Pharmacodynamics}

Baseline PTH values varied widely (10.5-1373.6 pg/mL; median [Q1, Q3] $161 \mathrm{pg} / \mathrm{mL}$ [123 pg/mL, $1263 \mathrm{pg} / \mathrm{mL}]$ ), as there were no inclusion criteria for minimum PTH levels. Reductions in serum PTH from baseline were observed at 2 underwent a 72-h period of PK, PD sampling, and safety monitoring. End of study procedures were conducted on day 4 ( $72 \mathrm{~h}$ post-dose). $\mathrm{t}$ SAE follow-up was conducted to day $30 . P D$ pharmacodynamic, $P K$ pharmacokinetic. $A E$ adverse evemt. $S A E$ serious adverse event

to $8 \mathrm{~h}$ post-dose (median $10.8 \%$ and $29.6 \%$, respectively) and returned towards baseline by 12 to $72 \mathrm{~h}$ (Fig. 4 or Table 3). Median percent reductions in PTH were greater at $8 \mathrm{~h}$ postdose in subjects $\geq 3$ years to $<6$ years old $(-42.2 \%)$ than in subjects $<3$ years old $(-5.2 \%)$; however, this observation should be interpreted with caution given the small subject numbers ( $N=3$ and $N=2$, respectively) (Fig. 4 or Table 3 ). Albumin-corrected serum calcium levels decreased slightly from baseline, reached nadirs at $8 \mathrm{~h}$ post-dose, and subse-
Table 2 Pharmacokinetic parameter estimates for cinacalcet in plasma after administration of $0.25 \mathrm{mg} / \mathrm{kg}$ cinacalcet to pediatric subjects $<6$ years old with CKD receiving dialysis

\begin{tabular}{|c|c|c|c|c|c|}
\hline Parameter & $t_{\max }(\mathrm{h})$ & $C_{\max }(\mathrm{ng} / \mathrm{mL})$ & $\mathrm{AUC}_{\text {last }}(\mathrm{h} * \mathrm{ng} / \mathrm{mL})$ & $\mathrm{AUC}_{\mathrm{inf}}(\mathrm{h} * \mathrm{ng} / \mathrm{mL})$ & $t_{1 / 2, \mathrm{z}}(\mathrm{h})$ \\
\hline \multicolumn{6}{|c|}{ Subjects $<3$ years old } \\
\hline$N$ & 4 & 4 & 4 & 4 & 4 \\
\hline Mean (SD) & NR & $1.51(0.820)$ & $7.21(5.27)$ & $8.31(6.28)$ & $2.73(0.952)$ \\
\hline Median & 0.75 & 1.36 & 6.04 & 6.68 & 2.60 \\
\hline Min-max & $0.50-3.1$ & $0.797-2.51$ & $2.84-13.9$ & $3.29-16.6$ & $1.83-3.87$ \\
\hline $\mathrm{CV} \%$ & NR & 54.5 & 73.1 & 75.7 & 34.9 \\
\hline \multicolumn{6}{|c|}{ Subjects $\geq 3$ to $<6$ years old } \\
\hline$N$ & 8 & 8 & 8 & 7 & 7 \\
\hline Mean (SD) & NR & $3.50(2.09)$ & $14.1(9.49)$ & $12.9(8.60)$ & $4.26(3.09)$ \\
\hline Median & 1.0 & 3.97 & 13.7 & 9.66 & 2.95 \\
\hline Min-max & $0.50-4.0$ & $0.818-5.75$ & $3.52-28.6$ & $3.90-25.4$ & $2.06-10.6$ \\
\hline CV\% & NR & 59.9 & 67.3 & 66.5 & 72.6 \\
\hline \multicolumn{6}{|c|}{ All subjects $<6$ years old } \\
\hline$N$ & 12 & 12 & 12 & 11 & 11 \\
\hline Mean (SD) & NR & $2.83(1.98)$ & $11.8(8.74)$ & $11.3(7.86)$ & $3.70(2.57)$ \\
\hline Median & 1.0 & 2.18 & 8.96 & 9.66 & 2.95 \\
\hline Min-max & $0.50-4.0$ & $0.797-5.75$ & $2.84-28.6$ & $3.29-25.4$ & $1.83-10.6$ \\
\hline CV\% & NR & 70.0 & 74.1 & 69.8 & 69.4 \\
\hline
\end{tabular}

$A U C$ area under the plasma-concentration-time curve, $A U C_{\text {inf }} \mathrm{AUC}$ from time zero to infinity, $A U C_{\text {last }} \mathrm{AUC}$ from time zero to time of last quantifiable concentration, $C K D$ chronic kidney disease, $C_{\max }$ maximum observed plasma concentration, $C V \%$ coefficient of variation, $\max$ maximum, min minimum, $N R$ not reported, $S D$ standard deviation, $t_{1 / 2, z}$ terminal half-life associated with $\lambda_{\mathrm{z}}$, $t_{\max }$ time to maximum concentration 


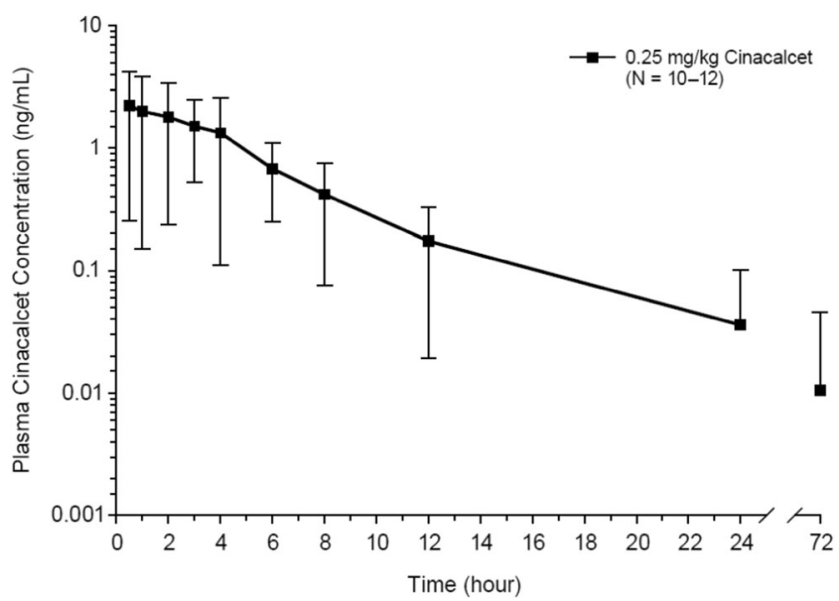

Fig. 2 Mean (SD) plasma cinacalcet log concentration-time profiles after administration of cinacalcet at $0.25 \mathrm{mg} / \mathrm{kg}$ to pediatric subjects with chronic kidney disease receiving dialysis $(n=10-12)$

quently returned to baseline (Fig. 5). Serum ionized calcium levels also decreased slightly from baseline, reached nadirs at $8 \mathrm{~h}$ post-dose in subjects $\geq 3$ years to $<6$ years old, at $12 \mathrm{~h}$ post-dose in subjects $<3$ years old and subsequently returned to baseline (Fig. 6).

\section{Pharmacokinetic/pharmacodynamic relationships}

Median percent reductions in plasma PTH concentration were associated with increases in cinacalcet concentration immediately after dosing (Fig. 7). Specifically, mean cinacalcet plasma concentration peaked at $1 \mathrm{~h}$ post-dose and gradually declined to undetectable levels by day 2 . As cinacalcet concentrations declined, plasma PTH concentrations transiently increased and returned to baseline levels by day 3 . As expected, slight reductions in total se-

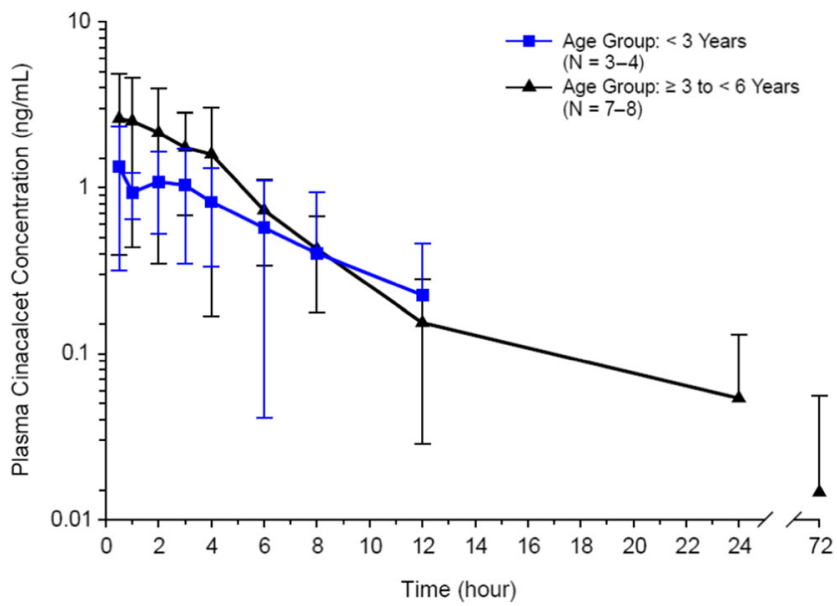

Fig. 3 Mean (SD) plasma cinacalcet log concentration-time profiles by age group after enteral administration of cinacalcet rum calcium (median percent reductions of up to $6.1 \%$ at $12 \mathrm{~h}$ post-dose) were observed and were followed by a return to baseline by the end of study. The overall pattern of changes from baseline in mean serum calcium and PTH concentrations was similar for both age groups. Decreased serum calcium and PTH corresponded inversely to changes in cinacalcet plasma concentrations up to $8 \mathrm{~h}$ after administration. As cinacalcet concentrations declined towards lower levels $(<0.5 \mathrm{ng} / \mathrm{mL})$, PTH and serum calcium increased and returned to baseline levels by day 3 (Fig. 7).

\section{Safety}

No major or unexpected safety findings were identified in this study [27]. Three subjects (25\%) experienced nonserious AEs (one subject had asymptomatic hypocalcemia, one subject had increased body temperature, and one subject experienced vomiting, catheter site hemorrhage, and expulsion). Overall, no clinically significant changes were observed in vital signs, hematology parameters, or clinical chemistry parameters, with the exception of median PTH and calcium concentrations.

\section{Discussion}

The present study evaluated the safety of cinacalcet, including the incidence of treatment-emergent AEs and clinically significant changes in physical examinations, laboratory safety tests, electrocardiograms ECG, and vital signs in dialyzed children $<6$ years of age. No subject experienced a serious $\mathrm{AE}$, and three subjects experienced nonserious AEs, including hypocalcemia, body temperature increase, and vomiting. No additional safety findings were identified.

We found that the pharmacokinetic parameters for cinacalcet in pediatric subjects $\leq 6$ years of age were similar to those observed in other studies (unpublished observations) when normalized by dose and body weight. Overall, no clinically meaningful differences in cinacalcet exposure were observed between the age groups due to extensive overlap, high inter-subject variability, and low plasma levels from 12 to $72 \mathrm{~h}$ after dosing (Table 2; Fig. $3)$. However, cinacalcet exposure levels $\left(C_{\max }\right.$ and AUC values) tended to be higher in subjects $\geq 3$ to $<6$ years old than in subjects $<3$ years old. Specifically, mean plasma cinacalcet $C_{\max }$ and AUC values were 1.6- to 2.3-fold higher in subjects $\geq 3$ to $<6$ years old compared with subjects $<3$ years old. Consequently, mean $C_{\max }(\mathrm{ng} / \mathrm{mL})$ concentrations for the younger age group was $\sim 57 \%$ lower than the older age group subjects and $\mathrm{AUC}_{\text {last }}$ was $\sim 49 \%$ 
Fig. 4 Median parathyroid hormone $(\mathrm{PTH})$ percent change from baseline after administration of cinacalcet at $0.25 \mathrm{mg} / \mathrm{kg}$ to pediatric subjects with chronic kidney disease $(\mathrm{CKD})$ receiving dialysis

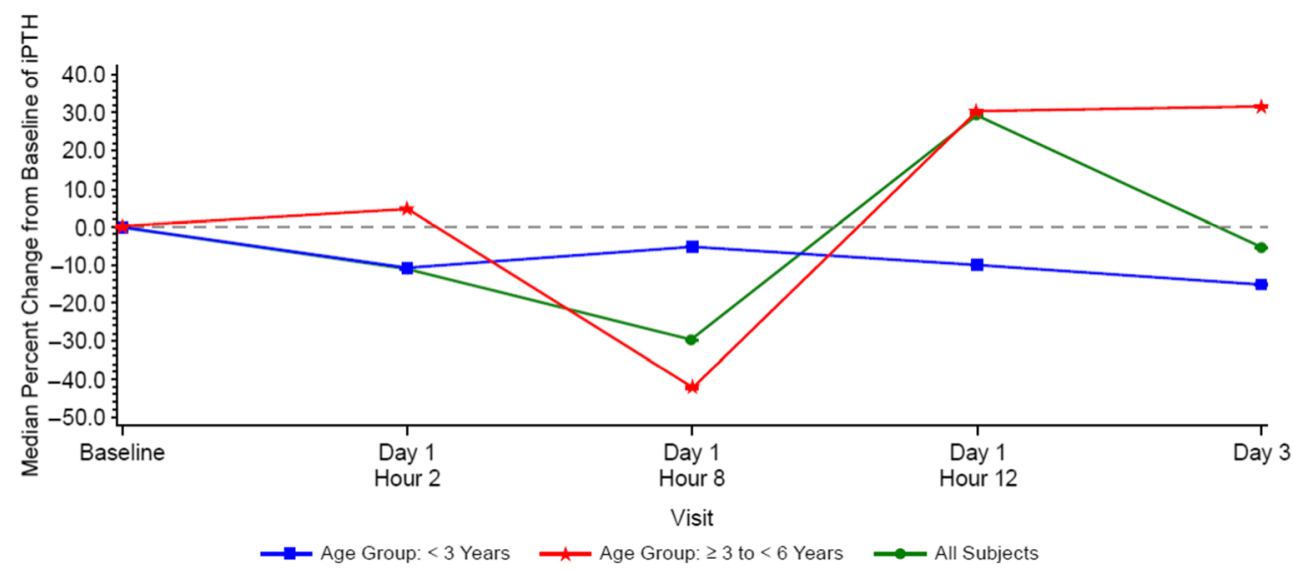

Table 3 Serum parathyroid hormone $(\mathrm{pg} / \mathrm{mL})$ at baseline and after administration of cinacalcet

\begin{tabular}{|c|c|c|c|}
\hline & $\begin{array}{l}\text { Age group: }<3 \text { years } \\
(N=4)\end{array}$ & $\begin{array}{l}\text { Age group: } \geq 3 \text { years to }<6 \text { years } \\
(N=8)\end{array}$ & $\begin{array}{l}\text { Total subjects } \\
(N=12)\end{array}$ \\
\hline \multicolumn{4}{|l|}{ Baseline } \\
\hline$n$ & 4 & 8 & 12 \\
\hline Median & 268.8 & 160.8 & 160.8 \\
\hline Q1, Q3 & $125.1,869.7$ & $102.4,1266.8$ & $122.6,1262.6$ \\
\hline Min, $\max$ & $119.1,1333.0$ & $10.5,1373.6$ & $10.5,1373.6$ \\
\hline \multicolumn{4}{|c|}{ Day 1 , hour 2 (\% change) } \\
\hline$n$ & 3 & 6 & 9 \\
\hline Median & -10.8 & 4.8 & -10.8 \\
\hline Q1, Q3 & $-18.5,19.1$ & $-53.3,53.0$ & $-18.5,23.1$ \\
\hline Min, $\max$ & $-18.5,19.1$ & $-89.0,6253.2$ & $-89.0,6253.2$ \\
\hline $\begin{array}{l}\text { Day } 1 \text { hour } 2 \\
\text { (median) }\end{array}$ & 331.3 & 135.6 & 156.2 \\
\hline \multicolumn{4}{|c|}{ Day 1 hour 8 (\% change) } \\
\hline$n$ & 2 & 3 & 5 \\
\hline Median & -5.2 & -42.2 & -29.6 \\
\hline Q1, Q3 & $-12.6,2.3$ & $-54.8,-29.6$ & $-42.2,-12.6$ \\
\hline Min, $\max$ & $-12.6,2.3$ & $-54.8,-29.6$ & $-54.8,2.3$ \\
\hline $\begin{array}{l}\text { Day } 1 \text {, hour } 8 \\
\text { (median) }\end{array}$ & 244.8 & 620.8 & 355.37 \\
\hline \multicolumn{4}{|c|}{ Day 1 , hour 12 (\% change) } \\
\hline$n$ & 1 & 4 & 5 \\
\hline Median & -10.0 & 30.3 & 29.4 \\
\hline Q1, Q3 & $-10.0,-10.0$ & $28.5,9471.7$ & $27.7,31.2$ \\
\hline Min, $\max$ & $-10.0,-10.0$ & $27.7,18,912.2$ & $-10.0,18,912.2$ \\
\hline $\begin{array}{l}\text { Day } 1 \text {, hour } 12 \\
\text { (median) }\end{array}$ & 1199.1 & 167.1 & 171.1 \\
\hline \multicolumn{4}{|c|}{ Day 3 (\% change) } \\
\hline$n$ & 3 & 6 & 9 \\
\hline Median & -15.0 & 31.8 & -5.4 \\
\hline Q1, Q3 & $-42.3,8.4$ & $-42.9,83.8$ & $-42.3,69.0$ \\
\hline Min, $\max$ & $-42.3,8.4$ & $-49.2,16,816.6$ & $-49.2,16,816.6$ \\
\hline Day 3 (median) & 345.4 & 515.6 & 345.4 \\
\hline
\end{tabular}

$N$ number of subjects in the analysis set, $n$ number of subjects with non-missing data at the time point of interest 
Fig. 5 Mean (SE) albumin corrected calcium $(\mathrm{cCa})$ over time by age group $(<3$ years $(n=4)$; age $\geq 3$ years $<6$ years $(n=8)$; all subjects $(n=12))$

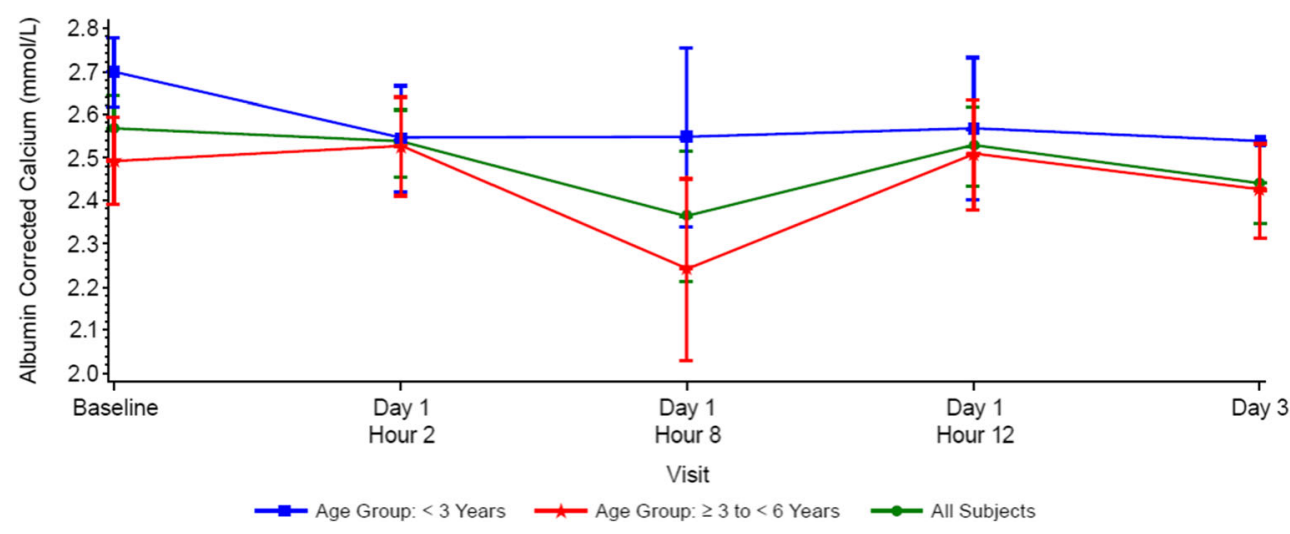

lower. The trend for higher cinacalcet exposure levels in the older age group is more apparent when examined within the first $4 \mathrm{~h}$ after dosing. Although sample sizes are small, one possible reason explaining this trend may be a transient and heightened increase in CYP3A4 expression at or above mature levels within 1 to 2 years immediately following birth that would result in similar or greater metabolism of cinacalcet and consequently lower AUC and $C_{\max }$ levels in the younger population [31]. Another possible explanation of the lower cinacalcet exposure levels in younger children is that they have a higher proportion of total body water [32] and thus, a greater volume of distribution of cinacalcet, resulting in lower measured plasma concentrations. In agreement with other pediatric studies, there were no notable effects of age, weight, body surface area, and BMI on the PK of cinacalcet (unpublished observations).

The $0.25 \mathrm{mg} / \mathrm{kg}$ dose employed had an observable PD effect as demonstrated by the lowering of PTH levels from baseline after cinacalcet administration, with a maximum reduction observed at $8 \mathrm{~h}$ post-dose. PTH levels decreased and were associated inversely with increases in plasma cinacalcet concentrations. A similar, but milder, inverse relationship between serum calcium and increased plasma cinacalcet concentrations was observed; however, only one subject had asymptomatic hypocalcemia. These results are consistent with the PD response and safety profile for cinacalcet in adults and children 6 to 18 years of age [27, 29, 33].

The dose used in the current study is approximately half the adult starting dose based on a milligrams per kilogram basis and is lower than the mean dose of $0.39 \mathrm{mg} / \mathrm{kg}$ previously studied in 12 subjects age 6 to $<18$ years with CKD receiving dialysis, where 2 subjects $(17 \%)$ experienced AEs (unpublished observations). In the current study, five treatment-emergent AEs were reported for $3(25 \%)$ of 12 subjects, including $1(25 \%)$ of 4 subjects $<3$ years old, and $2(25 \%)$ of 8 subjects $\geq 3$ years to $<6$ years old, and all were mild to moderate in severity. The safety profile and PD effect observed in the present study are similar to those observed in a previous cohort of older pediatric subjects with sHPT on dialysis [27-29].

The main limitation of the current study was the small sample size, which did not permit extensive subgroup analyses by age, and therefore, no formal statistical testing was performed. However, the results from this single-dose study provide valuable safety, pharmacokinetic, and pharmacodynamic information in a particularly young cohort of pediatric dialysis patients with SHPT.
Fig. 6 Mean (SE) ionized calcium (cCa) concentrations over time by age group $(<3$ years $(n=$ $4)$; age $\geq 3$ years $<6$ years $(n=8)$; all subjects $(n=12))$

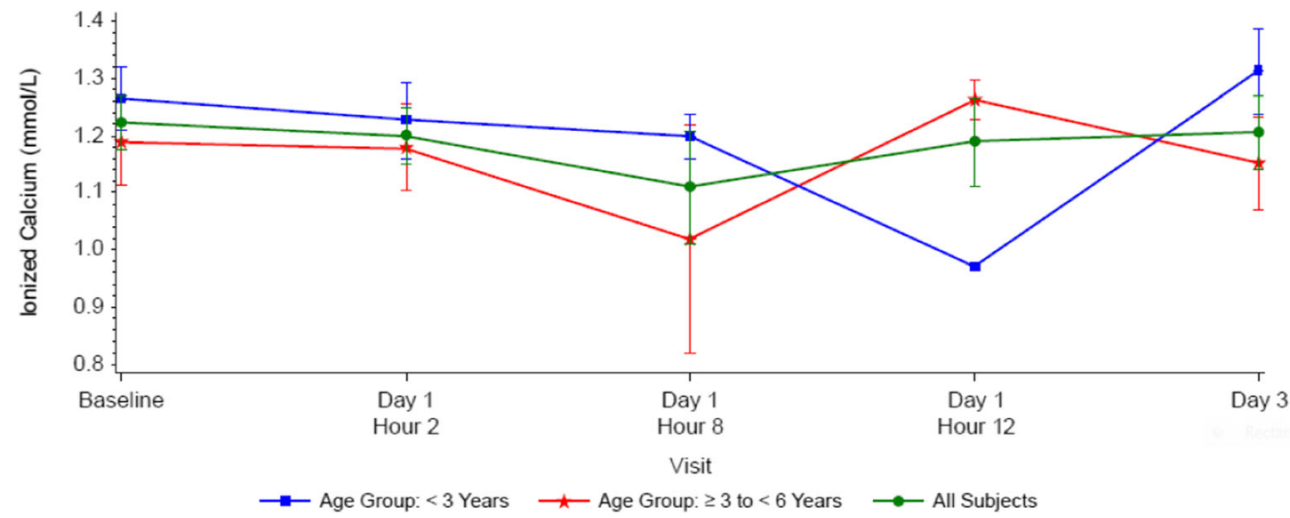


Fig. 7 Mean (SE) plasma cinacalcet, median (Q1, Q3) parathyroid hormone (PTH) percent change from baseline; mean (SE) total serum $\mathrm{Ca}$ concentration-time profiles in pediatric subjects with chronic kidney disease (CKD) receiving dialysis

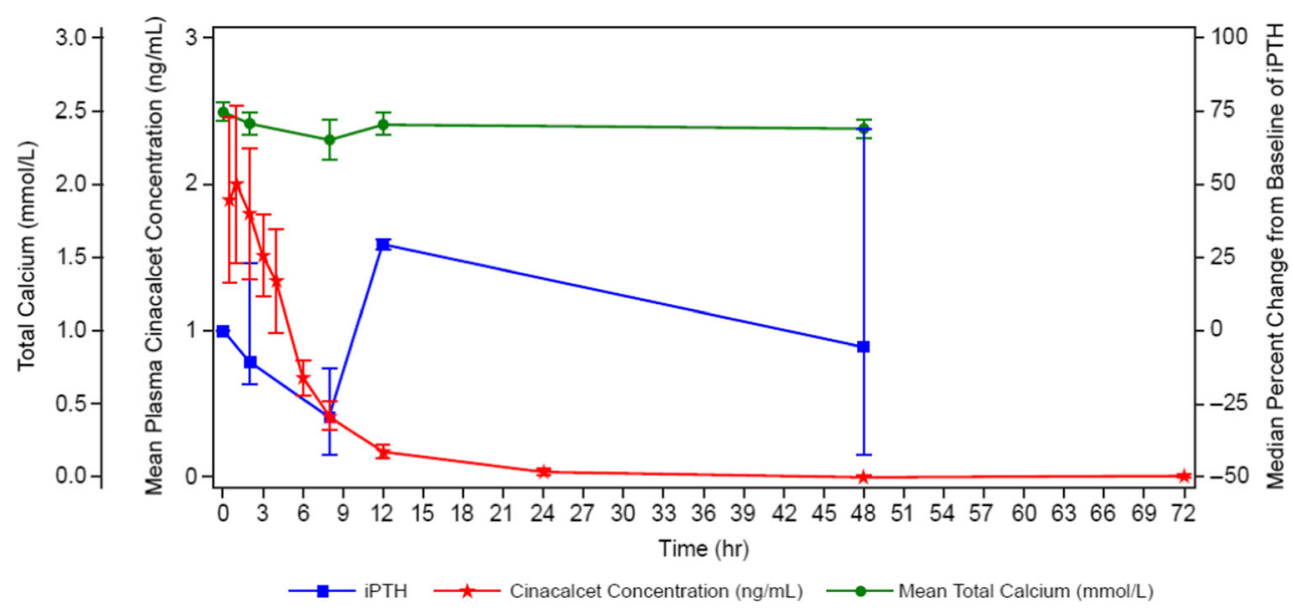

\section{Conclusions}

The observed safety profile and PD response in this study of cinacalcet in pediatric dialysis patients less than 6 years of age were consistent with that known for adult subjects with SHPT and in older pediatric dialysis subjects 6 to $<$ 18 years of age with SHPT. Results from this study demonstrate that a $0.25 \mathrm{mg} / \mathrm{kg}$ dose of cinacalcet was found to be safe and well-tolerated in children under 6 years of age, and the observed PD response suggests that repeated doses would result in a clinically meaningful decrease in PTH levels.

Acknowledgments The authors acknowledge Charles $\mathrm{M}$. Henley, $\mathrm{PhD}$, whose work was funded by Amgen Inc.; Holly Tomlin, MPH, CMPP (Amgen Inc. at time of writing, currently Tomlin Health Sciences Communications), and William W Stark, Jr., PhD (employee and stockholder, Amgen, Inc.), for their assistance with the writing of this manuscript.

Funding information This study was funded by Amgen, Inc.

\section{Compliance with ethical standards}

This study was conducted in accordance with applicable country regulations and International Conference on Harmonization (ICH) Good Clinical Practice (GCP). The study protocol (Amgen Protocol Number 20090005; ClinicalTrials.gov Identifier NCT01290029) was approved by the institutional review board/independent ethics committee (IRB/IEC) at each study center. All procedures performed in studies involving human participants were in accordance with the ethical standards of the institutional and/or national research committee and with the 1964 Helsinki declaration and its later amendments or comparable ethical standards. Informed consent was obtained from all parents or legally acceptable representatives.

Conflict of interest BE, EL, and WS are all employees and stockholders of Amgen, Inc. HZ is a full-time employee of Amgen, Inc. LY and BD were employees of Amgen, Inc. at the time the research was conducted. SS (S. Shahinfar Consulting, Inc.) and BW are paid consultants for Amgen, Inc. IS has research grants from Amgen, Inc. and Abbvie, Inc. and received consulting fees from Keryx, Inc. AP has nothing to disclose.
Data-sharing agreement There is a plan to share data. This may include de-identified individual patient data for variables necessary to address the specific research question in an approved data-sharing request and also related data dictionaries, study protocol, statistical analysis plan, informed consent form, and/or clinical study report. Data-sharing requests relating to data in this manuscript will be considered after the publication date, and (1) this product and indication (or other new use) have been granted marketing authorization in both the USA and Europe, or (2) clinical development discontinues and the data will not be submitted to regulatory authorities. There is no end date for eligibility to submit a data-sharing request for these data. Qualified researchers may submit a request containing the research objectives, the Amgen product(s), and Amgen study/ studies in scope, endpoints/outcomes of interest, statistical analysis plan, data requirements, publication plan, and qualifications of the researcher(s). In general, Amgen does not grant external requests for individual patient data for the purpose of re-evaluating safety and efficacy issues already addressed in the product labeling. A committee of internal advisors reviews requests. If not approved, a Data Sharing Independent Review Panel will arbitrate and make the final decision. Upon approval, information necessary to address the research question will be provided under the terms of a data-sharing agreement. This may include anonymized patient data and/or available supporting documents, containing fragments of analysis code where provided in analysis specifications. Further details are available at the following: http://www.amgen.com/ datasharing.

Open Access This article is distributed under the terms of the Creative Commons Attribution 4.0 International License (http:// creativecommons.org/licenses/by/4.0/), which permits unrestricted use, distribution, and reproduction in any medium, provided you give appropriate credit to the original author(s) and the source, provide a link to the Creative Commons license, and indicate if changes were made.

\section{References}

1. Ketteler M, Block GA, Evenepoel P, Fukagawa M, Herzog CA, McCann L, Moe SM, Shroff R, Tonelli MA, Toussaint ND, Vervloet MG, Leonard MB (2017) Executive summary of the 2017 KDIGO chronic kidney disease-mineral and bone disorder (CKD-MBD) guideline update: what's changed and why it matters. Kidney Int 92:26-36

2. Portale AA, Wolf MS, Messinger S, Perwad F, Juppner H, Warady BA, Furth SL, Salusky IB (2016) Fibroblast growth factor 23 and risk of CKD progression in children. Clin J Am Soc Nephrol 11: 1989-1998 
3. Silver J, Naveh-Many T (1994) Regulation of parathyroid hormone synthesis and secretion. Semin Nephrol 14:175-194

4. Parfitt AM (1997) The hyperparathyroidism of chronic renal failure: a disorder of growth. Kidney Int 52:3-9

5. Moe SM (2008) Disorders involving calcium, phosphorus, and magnesium. Prim Care 35:215-237 v-vi

6. Goodman WG, Quarles LD (2008) Development and progression of secondary hyperparathyroidism in chronic kidney disease: lessons from molecular genetics. Kidney Int 74:276-288

7. Cunningham J, Locatelli F, Rodriguez M (2011) Secondary hyperparathyroidism: pathogenesis, disease progression, and therapeutic options. Clin J Am Soc Nephrol 6:913-921

8. Wesseling-Perry K, Pereira RC, Tseng CH, Elashoff R, Zaritsky JJ, Yadin O, Sahney S, Gales B, Juppner H, Salusky IB (2012) Early skeletal and biochemical alterations in pediatric chronic kidney disease. Clin J Am Soc Nephrol 7:146-152

9. Groothoff JW, Offringa M, Van Eck-Smit BL, Gruppen MP, Van De Kar NJ, Wolff ED, Lilien MR, Davin JC, Heymans HS, Dekker FW (2003) Severe bone disease and low bone mineral density after juvenile renal failure. Kidney Int 63:266-275

10. Wesseling-Perry K, Salusky IB (2013) Chronic kidney disease: mineral and bone disorder in children. Semin Nephrol 33:169-179

11. Denburg MR, Kumar J, Jemielita T, Brooks ER, Skversky A, Portale AA, Salusky IB, Warady BA, Furth SL, Leonard MB (2016) Fracture burden and risk factors in childhood CKD: results from the CKiD cohort study. J Am Soc Nephrol 27:543-550

12. Sanchez CP (2003) Secondary hyperparathyroidism in children with chronic renal failure: pathogenesis and treatment. Paediatr Drugs 5:763-776

13. Kuizon BD, Salusky IB (1999) Growth retardation in children with chronic renal failure. J Bone Miner Res 14:1680-1690

14. Goodman WG, Goldin J, Kuizon BD, Yoon C, Gales B, Sider D, Wang Y, Chung J, Emerick A, Greaser L, Elashoff RM, Salusky IB (2000) Coronary-artery calcification in young adults with end-stage renal disease who are undergoing dialysis. N Engl J Med 342: $1478-1483$

15. Mathias R, Salusky I, Harman W, Paredes A, Emans J, Segre G, Goodman W (1993) Renal bone disease in pediatric and young adult patients on hemodialysis in a children's hospital. J Am Soc Nephrol 3:1938-1946

16. Khouzam NM, Wesseling-Perry K, Salusky IB (2015) The role of bone in CKD-mediated mineral and vascular disease. Pediatr Nephrol 30:1379-1388

17. Schmitt CP, Mehls O (2011) Mineral and bone disorders in children with chronic kidney disease. Nat Rev Nephrol 7:624-634

18. Wesseling-Perry K, Pereira RC, Sahney S, Gales B, Wang HJ, Elashoff R, Juppner H, Salusky IB (2011) Calcitriol and doxercalciferol are equivalent in controlling bone turnover, suppressing parathyroid hormone, and increasing fibroblast growth factor-23 in secondary hyperparathyroidism. Kidney Int 79:112119

19. Sosa JA, Tuggle CT, Wang TS, Thomas DC, Boudourakis L, Rivkees S, Roman SA (2008) Clinical and economic outcomes of thyroid and parathyroid surgery in children. J Clin Endocrinol Metab 93:3058-3065
20. Burke JF, Chen H, Gosain A (2014) Parathyroid conditions in childhood. Semin Pediatr Surg 23:66-70

21. Block GA, Martin KJ, de Francisco AL, Turner SA, Avram MM, Suranyi MG, Hercz G, Cunningham J, Abu-Alfa AK, Messa P, Coyne DW, Locatelli F, Cohen RM, Evenepoel P, Moe SM, Fournier A, Braun J, McCary LC, Zani VJ, Olson KA, Drueke TB, Goodman WG (2004) Cinacalcet for secondary hyperparathyroidism in patients receiving hemodialysis. N Engl J Med 350: $1516-1525$

22. Malluche HH, Monier-Faugere MC, Wang G, Fraza OJ, Charytan C, Coburn JW, Coyne DW, Kaplan MR, Baker N, McCary LC, Turner SA, Goodman WG (2008) An assessment of cinacalcet $\mathrm{HCl}$ effects on bone histology in dialysis patients with secondary hyperparathyroidism. Clin Nephrol 69:269-278

23. Palmer SC, Nistor I, Craig JC, Pellegrini F, Messa P, Tonelli M, Covic A, Strippoli GF (2013) Cinacalcet in patients with chronic kidney disease: a cumulative meta-analysis of randomized controlled trials. PLoS Med 10:e1001436

24. Ballinger AE, Palmer SC, Nistor I, Craig JC, Strippoli GF (2014) Calcimimetics for secondary hyperparathyroidism in chronic kidney disease patients. Cochrane Database Syst Rev:Cd006254

25. Behets GJ, Spasovski G, Sterling LR, Goodman WG, Spiegel DM, De Broe ME, D'Haese PC (2015) Bone histomorphometry before and after long-term treatment with cinacalcet in dialysis patients with secondary hyperparathyroidism. Kidney Int 87:846-856

26. Evenepoel P, Cooper K, Holdaas H, Messa P, Mourad G, Olgaard K, Rutkowski B, Schaefer H, Deng H, Torregrosa JV, Wuthrich RP, Yue S (2014) A randomized study evaluating cinacalcet to treat hypercalcemia in renal transplant recipients with persistent hyperparathyroidism. Am J Transplant 14:2545-2555

27. Muscheites J, Wigger M, Drueckler E, Fischer DC, Kundt G, Haffner D (2008) Cinacalcet for secondary hyperparathyroidism in children with end-stage renal disease. Pediatr Nephrol 23: 1823-1829

28. Platt C, Inward C, McGraw M, Dudley J, Tizard J, Burren C, Saleem MA (2010) Middle-term use of cinacalcet in paediatric dialysis patients. Pediatr Nephrol 25:143-148

29. Padhi D, Langman CB, Fathallah-Shaykh S, Warady BA, Salusky IB, Lee E, Wang C, Posvar E (2012) An open-label study to evaluate a single-dose of cinacalcet in pediatric dialysis subjects. Pediatr Nephrol 27:1953-1959

30. Padhi D, Harris R (2009) Clinical pharmacokinetic and pharmacodynamic profile of cinacalcet hydrochloride. Clin Pharmacokinet 48:303-311

31. Hines RN (2013) Developmental expression of drug metabolizing enzymes: impact on disposition in neonates and young children. Int J Pharm 452:3-7

32. Friis-Hansen BJ, Holiday M, Stapleton T, Wallace WM (1951) Total body water in children. Pediatrics 7:321-327

33. Smith JM, Stablein DM, Munoz R, Hebert D, McDonald RA (2007) Contributions of the transplant registry: the 2006 annual report of the north American pediatric renal trials and collaborative studies (NAPRTCS). Pediatr Transplant 11:366-373 